\title{
Negative Moderating Effect of General Self-Efficacy on the Relationship between Need for Cognition and Cognitive Effort
}

\author{
Kishore Gopalakrishna Pillai, University of Leeds \\ Ronald E. Goldsmith, Florida State University \\ Michael Giebelhausen, Cornell University
}

This study demonstrates the negative moderating effect of general self-efficacy on the relationship between need for cognition, which refers to stable individual differences in people's tendencies to engage in and enjoy cognitive activity, and cognitive effort. This negative moderating effect of general self-efficacy has been termed "plasticity." Scholars assume the relationship between need for cognition and cognitive effort is true by definition. The study uses data from 144 U.S. college students and employs moderated regression analysis followed by subgroup analysis to demonstrate plasticity. The results set a boundary condition to the generally presumed relationship between need for cognition and cognitive effort, thereby improving the understanding of how these phenomena are related.

General self-efficacy is a relatively stable, trait-like, generalized competence belief (Chen, Gully, \& Eden, 2001). General self-efficacy is positively related to the abilities of individuals and the motivation of individuals. Because it is related to greater ability and motivation, general self-efficacy attenuates other relationships that depend on ability and motivation. Hence, the construct plays a moderating role on the relationship between other constructs that operate on the basis of enhanced ability or motivation. This paper argues the case for a negative moderating effect of general self-efficacy on such a relationship - that between need for cognition, which refers to stable individual differences in people's tendencies to engage in and to enjoy cognitive activity (Cacioppo \& Petty, 1982), and cognitive effort. Research on individuals in work situations often finds a negative moderating effect of general selfefficacy-termed "behavioral plasticity" (Brockner, 1988; Eden \& Aviram, 1993). The present study demonstrates plasticity (negative moderating effect of general self-efficacy) of the relationship between need for cognition and cognitive effort. 
Behavioral plasticity research focuses on the moderating effect of general self-efficacy on the relationship between external influences, such as experimental treatments and interventions, and their consequences, such as motivation and performance. Since ability and motivation can influence the effects of internal variables such as need for cognition, the plasticity effect should be observed in the effects of such internal variables. Demonstrating this effect extends the research on behavioral plasticity beyond the focus on external influences.

As noted above, this study examines the negative moderating effect of general self-efficacy on the relationship between need for cognition and cognitive effort. The relationship between need for cognition and cognitive effort is presumed to exist by definition because need for cognition drives cognitive effort. Since general self-efficacy is positively related to greater ability and motivation, the former could potentially moderate this relationship, and the demonstration of this effect advances current theory by setting a boundary condition for the generally presumed relationship between need for cognition and cognitive effort. Thus, this study has two main contributions. It establishes a boundary condition for the relationship between need for cognition and cognitive effort. It also extends research on behavioral plasticity by applying the effect to internal factors such as need for cognition.

\section{General Self-efficacy}

According to Bandura (1986), self-efficacy refers to people's judgments of their capabilities to organize and perform specific action such that designated types of performances are attained (Combs \& Luthans, 2007). The focus of the construct is not on the skills one has, but rather on judgments of what one can do with his/her skills (Bandura, 1986). Research in organizational behavior reports consistent positive relationships between self-efficacy and performance (Barling \& Beattie, 1983; Stajkovic \& Luthans, 1998).

Bandura (1977) stated that self-efficacy has three dimensions: magnitude, strength, and generality. Magnitude refers to the level at which a person believes he or she can perform. Strength, on the other hand, reflects the person's confidence that he or she will be able to perform at that level. Generality refers to the extent to which self-efficacy in one situation extends to other situations (Maurer \& Pierce, 1998). Early research on self-efficacy examined the dimensions of magnitude and strength. The focus on these two dimensions follows Bandura's emphasis (1977) on the domain specificity of selfefficacy. Recent research has focused on the construct of general self-efficacy. Unlike self-efficacy, which is a relatively malleable, task-specific belief, general self-efficacy is a relatively stable, trait-like, generalized competence belief (Chen, et al., 2001). 
Following Kanfer and Heggestad's distinction (1997) between trait and state individual differences in motivation and affect, researchers use a state versus trait distinction to understand the difference between self-efficacy and general self-efficacy. Eden (1988) and Judge, Locke, and Durham (1997) conceptualize self-efficacy as a motivational state and general self-efficacy as a motivational trait (Chen, et al., 2001). Though the constructs differ in scope (i.e., general or specific) of the focal performance domain, both general self-efficacy and self-efficacy are related to beliefs about one's ability to achieve desired outcomes (Eden, 1988; Chen, et al., 2001). However, it should be noted that general self-efficacy is much more resistant to transient influences, compared to self-efficacy (Eden, 1988; Chen, et al., 2001). Scholars propose that one of the key antecedents of general self-efficacy is the accumulation of prior experiences (Shelton, 1990; Chen, et al., 2001). General self-efficacy develops over the course of one's life as one experiences successes and failures in different contexts and task domains (Shelton, 1990; Chen, et al., 2001). General self-efficacy influences the general set of expectations that individuals carry with them when they encounter new situations (Sherer, Maddux, Mercandante, Prentice-Dunn, Jacobs, \& Rogers, 1982) and, in turn, influences behaviors and responses in new situations (Saks \& Ashforth, 2000).

\section{Behavioral Plasticity}

According to the behavioral plasticity hypothesis, individuals low in general self-efficacy are more amenable and susceptible to external cues or environmental and social influences and, therefore, are more malleable or behaviorally plastic compared to individuals with high general self-efficacy (Brockner, 1988; Eden \& Aviram, 1993; Pierce, Gardner, Dunham, \& Cummings, 1993; Eden \& Zuk, 1995). Research by Eden and colleagues has shown that plasticity in the effects of experimental treatments on motivation and performance is greater among individuals with low general self-efficacy (Eden \& Aviram, 1993; Eden \& Zuk, 1995); that is, general self-efficacy negatively moderates the relationships between experimental treatments and their consequences (motivation or performance). For instance, in their study of seasickness among cadets, Eden and Zuk (1995) found that the intervention to reduce seasickness was more effective for cadets with low general self-efficacy than for those high in general self-efficacy.

Citing Brockner's work (1988), Saks and Ashforth (2000) provided two reasons for the behavioral plasticity effect. Among those with low general self-efficacy, the uncertainty regarding appropriateness of their attitudes and behaviors renders them more susceptible to influences from external sources. Also, general self-efficacy engenders self-confidence, and hence individuals who are high in general self- 
efficacy are able to cope with stressors better than individuals who are low in general self-efficacy (Brockner, 1988; Pierce, et al., 1993; Saks \& Ashforth, 2000).

\section{Plasticity of the Relationship Between Need for Cognition and Cognitive Effort}

Need for cognition refers to stable individual differences in people's tendencies to engage in and to enjoy cognitive activity (Cacioppo \& Petty, 1982). Research identifies need for cognition as the primary individual- difference variable that influences individuals' motivation to think (Haugtvedt \& Petty, 1992). Individuals who are high in need for cognition enjoy thinking. They also enjoy complex tasks and are more likely to engage in analytical processing of information (Haugtvedt \& Petty, 1992), are more likely to be persuaded by strong arguments (Priester \& Petty, 1995), and show a greater propensity to search for more information (Cacioppo, Petty, Feinstein, \& Jarvis, 1996).

Considerable research has focused on need for cognition. Individuals with high need for cognition are shown to have a more positive attitude toward problem solving than individuals with low need for cognition (Cacioppo, et al., 1996). Individuals with high need for cognition prefer oral or written information to visual information (Sojka \& Giese, 2001). Building on the reasoning that the attitudes of individuals with low need for cognition in response to persuasive communication are affected less by message-relevant arguments and more by peripheral cues, Zhang (1996) found that the persuasive effect of humor in advertisements is greater among those with low need for cognition. A general finding is that need for cognition promotes cognitive effort of various kinds. This is expected as, by definition, need for cognition is related to cognitive effort. Recent research identifies "commitment to cognitive effort" as a dimension of the need for cognition construct (Lord \& Putrevu, 2006).

Though need for cognition and cognitive effort are intrinsically related, scant research examines the qualifiers of the relationship between these two variables. This is rather surprising, as cognitive effort itself has attracted considerable research across disciplines such as psychology and marketing (e.g., Newell \& Simon, 1990). For example, people are cognitive "misers" (Fiske \& Taylor, 1984) who allocate their limited cognitive resources in a judicious manner (Russo \& Dosher, 1983). Using heuristics to reduce cognitive effort has also been observed (Johnson, Payne, \& Bettman, 1988). Garbarino and Edell (1997) examined the effect of cognitive effort on choice tasks through process-induced negative affect, reporting that cognitive effort produces negative affect, thus adversely influencing the choice of the alternative that was more difficult to process.

Given the research focus on need for cognition and cognitive effort and the positive relationship between these two constructs, extending understanding of this domain will be achieved through a study 
of moderating factors of the relationship between need for cognition and cognitive effort. This is especially so in consumer research where a positive relationship between need for cognition and cognitive effort leads to the presumption that consumers high in need for cognition are more receptive

to information and engage in greater processing of information. Accordingly, the present study advances the understanding of the boundary conditions of the relationship between need for cognition and cognitive effort by proposing a moderating effect of general self-efficacy. The choice of the moderator variable was motivated by the research on behavioral plasticity.

The relationship between need for cognition and cognitive effort is likely to be stronger among individuals with low general self-efficacy. When general self-efficacy is low, need for cognition, as expected, boosts cognitive effort (Cacioppo \& Petty, 1982). But, as argued earlier, individuals with high general self-efficacy are motivated to devote greater effort due to their higher expectation of success. This effect will occur irrespective of need for cognition. Therefore, when general self-efficacy is higher, the relationship between need for cognition and cognitive effort will be weaker, based on the motivational effect of general self-efficacy, an effect that is likely to be strong as failure leads to dissonance (Festinger, 1957). Moreover, according to self-consistency theory, individuals strive to maintain their perception of greater efficacy and therefore act in a manner consistent with the self views (Korman, 1970; Swann, 1996), which translates to greater effort. It is expected that general selfefficacy will negatively moderate the effect of need for cognition on cognitive effort such that the effect is stronger among those with low general self-efficacy.

\section{Method}

\section{Participants and Design}

The sample size was 144 and comprised 37\% (53) men and 63\% (91) women. The age of the respondents ranged from 19 to $24 \mathrm{yr}$. $(M=20.65)$.

The design for the study followed the classic design for studying cognitive processing (Petty \& Cacioppo, 1986). Participants were recruited from a large undergraduate business course. An incentive of a $1 \%$ increase in their course grade was used to encourage participation. For this particular study, the students were told they would be completing three brief unrelated studies being conducted by different researchers at the school. Access to the online studies was available only via the school's online subject pool application. This particular study was the second in a series of three. 
Participants initially completed a series of individual difference measures. The order was counterbalanced among participants. Following this, participants read a passage that described a proposal, currently under consideration by the university, requiring that all future testing be conducted via essay exams. A thought-listing task followed whereby participants were allowed to record as many thoughts as they wished regarding the essay exam proposal.

\section{Measures}

Need for cognition was measured using an 18-item scale (Cacioppo \& Petty, 1982). Responses were obtained on a 7-point response format with anchors 1: Strongly agree and 7: Strongly disagree. Need for cognition was computed as the average of the 18 items, after recoding the nine reverse-scored items. Reported internal consistency reliability ranged from .83 to .97 (cacioppo, et al., 1996).

General self-efficacy was measured using an 8-item scale (Chen, et al., 2001). Responses were obtained on a 7-point response format with anchors 1: Strongly agree and 7: Strongly disagree. General self-efficacy was computed as the average of the scores of the eight items. Chen, et al. (2001) reported Cronbach's alphas from .85 to .90 .

Cognitive effort was measured using the number of thoughts listed in a thought-listing task (Cacioppo \& Petty, 1982; Petty, Cacioppo, \& Schumann, 1983).

\section{Results}

Table 1 presents descriptive statistics for the three measures. Correlations between (a) need for cognition and general self-efficacy $(.35, p<.01 ; 95 \% \mathrm{Cl}=.19, .48)$ and $(\mathrm{b})$ need for cognition and cognitive effort $(.28, p<.01 ; 95 \% \mathrm{Cl}=.12, .43)$ were statistically significant but that between general selfefficacy and cognitive effort $(.07 ; p<.4)$ was not.

\section{Scale Reliabilities}

Reliabilities of multi-item scales were examined through coefficient alpha. The 18-item Need for Cognition Scale had a Cronbach's alpha reliability of .87, while the 8-item general self-efficacy scale had alpha $=.95$.

\section{Test of the Moderation}

Moderated regression analysis was used, with cognitive effort as the dependent variable, and need for cognition, general self-efficacy, and the product of need for cognition and general self-efficacy 
as the independent variables. Since need for cognition and general self-efficacy were statistically significantly correlated, the interaction term was computed after mean-centering the independent variables (Aiken \& West, 1991). Collinearity was not an issue as the highest variance inflation factor (VIF) obtained was 1.26 .

The regression model (Table 2) supported the proposed negative moderating effect of general self-efficacy. To understand the interaction better, the sample was split into high general self-efficacy (> 6 ) and low general self-efficacy $(\leq 6)$ groups. It can be seen from Table 2 that a significant positive relationship between need for cognition and cognitive effort was obtained for the low general selfefficacy group. But for the high general self-efficacy group, the relationship was not statistically significant $(p=.12)$.

\section{TABLE 1}

Descriptive Statistics

\begin{tabular}{lccc}
\hline \hline Variable Name & Range & $M$ & $S D$ \\
\hline Need for Cognition & $2.06-6.72$ & 4.71 & 0.79 \\
General Self-efficacy & $3.75-7.00$ & 6.03 & 0.68 \\
Cognitive Effort & $1.00-7.00$ & 2.96 & 1.46 \\
\hline
\end{tabular}

TABLE 2

Regression of Cognitive Effort on Need For Cognition and General Self-efficacy in the Total and Subgroups With Low and High General Self-efficacy

\begin{tabular}{lrrrrrr}
\hline \hline \multicolumn{1}{c}{ Variable Name } & B & $S E$ & $\beta$ & $t$ & $p$ & VIF \\
\hline Total sample & & & & & & \\
$\quad$ Need for cognition & .61 & .16 & .33 & 3.82 & .001 & 1.20 \\
$\quad$ General self-efficacy & -.19 & .19 & -.09 & -.99 & .33 & 1.26 \\
$\quad$ NfC $\times$ GSE & -.42 & .21 & -.18 & -2.06 & .04 & 1.13 \\
$\quad$ Adjusted $R^{2}=.09, F_{3,140}=5.63, p=.001$ & & & & & & \\
$\quad \begin{array}{l}\text { High general self-efficacy }(n=74) \\
\quad \text { Need for cognition }\end{array}$ & .33 & .21 & .18 & 1.59 & .12 & \\
$\quad$ Adjusted $R^{2}=.02, F=2.53$ & & & & & & \\
$\quad \begin{array}{l}\text { Low general self-efficacy }(n=70) \\
\quad \text { Need for cognition }\end{array} \quad .94$ & .22 & .46 & 4.32 & .001 & \\
$\quad$ Adjusted $R^{2}=.20, F=18.67$ & & & & & & \\
\hline
\end{tabular}

\section{Discussion}

The study extends the understanding of need for cognition by demonstrating the negative moderating influence of general self-efficacy on the relationship between need for cognition and cognitive effort. The results illustrate the behavioral plasticity phenomenon in which relationships that 
depend on ability or motivation are different for individuals with low versus high general self-efficacy, and extend it from external influences to internal states. The study provides support for the argument that general self-efficacy operates through higher ability and motivation and hence attenuates the relationship between other variables that operate through ability and/or motivation and their consequences, providing an alternative explanation of the plasticity effect.

The moderating role of need for cognition in the relationships between other constructs has been recorded by researchers. A basic argument underlying the moderating effects is that need for cognition promotes cognitive effort. The findings have the potential to inform current research in several domains where need for cognition has been employed, such as decision making and attitude change. For example, Kim and Kramer (2006) reported a moderating effect of need for cognition on consumer response to multidimensional prices, such that consumers with low need for cognition were more likely to purchase products that listed price and relative surcharge separately. Nan (2009) found that need for cognition moderated the negative effect of source credibility on attitude certainty in people who have low need for cognition. Need for cognition has also been found to moderate the persistence and resistance of attitude changes (Haugtvedt \& Petty, 1992). An interesting line of enquiry would be to study whether such moderation effects hold among individuals with high and low general self-efficacy.

One of the key limitations of the study is the reliance on cross-sectional data and the survey method. None of the variables, involvement, knowledge, general self-efficacy, or need for cognition was manipulated. Replication of the study with appropriate manipulations will provide a more stringent test of the hypotheses. The issue of student subjects also needs addressing. In order to enhance the external validity of the findings, the study needs to be replicated among shopping consumers drawn from the general population.

\section{References}

Aiken, L. S., \& West, S. G. (1991) Multiple regression: testing and interpreting interactions. Newbury Park, CA: Sage.

Bandura, A. (1977) Self-efficacy: toward a unifying theory of behavioral change. Psychological Review, 84, 191-215.

Bandura, A. (1986) Social foundations of thought and action: a social cognitive theory. Englewood Cliffs, NJ: Prentice Hall. 
Barling, J., \& Beattie, R. (1983) Self-efficacy beliefs and sales performance. Journal of Organizational Behavior Management, 5, 41-51.

Brockner, J. (1988) Self-esteem at work: research, theory, and practice. Lexington, MA: Lexington Books.

Cacioppo, J. T., \& Petty, R. E. (1982) The need for cognition. Journal of Personality and Social Psychology, $42,116-131$.

Cacioppo, J. T., Petty, R. E., Feinstein, J. A., \& Jarvis, W. B. G. (1996) Dispositional differences in cognitive motivation: the life and times of individuals varying in need for cognition. Psychological Bulletin, $119,197-253$.

Chen, G., Gully, S. M., \& Eden, D. (2001) Validation of a new general self-efficacy scale. Organizational Research Methods, 4, 62-83.

Combs, G. M., \& Luthans, F. (2007) Diversity training: analysis of the impact of self- efficacy. Human Resource Development Quarterly, 18, 91-120.

Eden, D. (1988) Pygmalion, goal setting, and expectancy: compatible ways to boost productivity. Academy of Management Review, 13, 639-652.

Eden, D., \& Aviram, A. (1993) Self-efficacy training to speed reemployment: helping people to help themselves. Journal of Applied Psychology, 78, 352-360.

Eden, D., \& Zuk, Y. (1995) Seasickness as a self-fulfilling prophecy: raising self-efficacy to boost performance at sea. Journal of Applied Psychology, 80, 628-635.

Festinger, L. (1957) A theory of cognitive dissonance. Stanford, CA: Stanford Univer. Press.

Fiske, S. T., \& Taylor, S. E. (1984) Social cognition. New York: Random House. Garbarino, E. C., \& Edell, J. A. (1997) Cognitive effort, affect, and choice. Journal of Consumer Research, 24, 147-158.

Haugtvedt, C. P., \& Petty, R. E. (1992) Personality and persuasion: need for cognition moderates the persistence and resistance of attitude changes. Journal of Personality and Social Psychology, 63, 308-319.

Johnson, E. J., Payne, J. W., \& Bettman, J. R. (1988) Information displays and preference reversals. Organizational Behavior and Human Decision Processes, 42, 1-21.

Judge, T. A., Locke, E. A., \& Durham, C. C. (1997) The dispositional causes of job satisfaction: a core evaluations approach. Research in Organizational Behavior, 19, 151-188.

Kanfer, R., \& Heggestad, E. D. (1997) Motivational traits and skills: a person-centered approach to work motivation. Research in Organizational Behavior, 19, 1-56.

Kim, H. M., \& Kramer, T. (2006) The moderating effects of need for cognition and cognitive effort on responses to multi-dimensional prices. Marketing Letters, 17, 193-203. 
Korman, A. K. (1970) Toward an hypothesis of work behavior. Journal of Applied Psychology, 54, 31-41.

Lord, K. R., \& Putrevu, S. (2006) Exploring the dimensionality of the Need for Cognition Scale. Psychology and Marketing, 23, 11-34.

Maurer, T. J., \& Pierce, H. R. (1998) A comparison of Likert scale and traditional measures of selfefficacy. Journal of Applied Psychology, 83, 324-329.

Nan, X. (2009) The influence of source credibility on attitude certainty: exploring the moderating effects of timing of source identification and individual need for cognition. Psychology and Marketing, 26, 321-332.

Newell, A., \& Simon, H. A. (1990) Computer science as empirical enquiry: symbols and search. In J. L. Garfield (Ed.), Foundations of cognitive science: the essential readings. New York: Paragon. Pp. 113-138.

Petty, R. E., \& Cacioppo, J. T. (1986) Communication and persuasion: central and peripheral routes to attitude change. New York: Springer-Verlag.

Petty, R. E., Cacioppo, J. T., \& Schumann, D. (1983) Central and peripheral routes to advertising effectiveness: the moderating role of involvement. Journal of Consumer Research, 10, 135-146.

Pierce, J. L., Gardner, D. G., Dunham, R. B., \& Cummings, L. L. (1993) Moderation by organization-based self-esteem of role condition-employee response relation- ships. Academy of Management Journal, 36, 271-288.

Priester, J. R., \& Petty, R. E. (1995) Source attribution and persuasion: perceived honesty as a determinant of message scrutiny. Personality and Social Psychology Bulletin, 21, 637-654.

Russo, J. E., \& Dosher, B. A. (1983) Strategies for multiattribute binary choice. Journal of experimental Psychology: Learning, Memory, and Cognition, 9, 676-696.

Saks, A. M., \& Ashforth, B. E. (2000) The role of dispositions, entry stressors, and behavioral plasticity theory in predicting newcomers' adjustment to work. Journal of Organizational Behavior, 21, 4362.

Shelton, S. H. (1990) Developing the construct of general self-efficacy. Psychological Reports, 66, 987994.

Sherer, M., Maddux, J. E., Mercandante, B., Prentice-Dunn, S., Jacobs, B., \& Rogers, R. W. (1982) The Self-efficacy Scale: construction and validation. Psychological Reports, 51, 663-671.

Sojka, J., \& Giese, J. (2001) The influence of personality traits on the processing of visual and verbal information. Marketing Letters, 12, 91-106. 
Stajkovic, A. D., \& Luthans, F. (1998) Self-efficacy and work-related performance: a meta-analysis. Psychological Bulletin, 124, 240-261.

Swann, W. B. (1996) Self-traps: the elusive quest for higher self-esteem. New York: West- view.

Zhang, Y. (1996) Responses to humorous advertising: the moderating effect of need for cognition. Journal of Advertising, 25, 15-32. 